\title{
An Open-Label Study Evaluating the Performance of the Dose Indicator in a Metered Dose Inhaler Delivering Glycopyrrolate and Formoterol Fumarate in Patients with Moderate-to-Very Severe Chronic Obstructive Pulmonary Disease
}

\author{
Krishna Pudi, MD, Gregory Feldman, MD, ${ }^{2}$ Faisal Fakih, MD, ${ }^{3}$ Peter Mack, $\mathrm{PhD},{ }^{4}$ Andrea Maes, $\mathrm{PhD},{ }^{5}$ \\ Shahid Siddiqui, MD, MHSA, ${ }^{6}$ Earl St. Rose, MBA, MS, ${ }^{5}$ and Colin Reisner, MD, FCCP ${ }^{5,6}$
}

\begin{abstract}
Background: GFF MDI is a glycopyrrolate/formoterol fumarate fixed-dose combination metered dose inhaler formulated using co-suspension delivery technology. This open-label, single-arm multicenter study (NCT02268396) evaluated the accuracy, reliability, and functionality of the GFF MDI AeroCount ${ }^{\circledR}$ dose indicator when used by patients with chronic obstructive pulmonary disease (COPD).

Patients and Methods: The study enrolled subjects (40-80 years of age) with an established clinical history ( $\geq 6$ months) of COPD, who completed an electronic diary twice daily to record study-drug administration time, the number of actuations used, and pre- and post-dose dose indicator readings. The primary endpoint was the percentage of devices for which the number of subject-reported actuations was consistent $( \pm 20$ actuations $)$ with the dose indicator-based actuation count (equal to 130 minus the dose indicator reading) at the end of the treatment period (4 weeks). Safety was monitored throughout the study.

Results: A total of 138 subjects with moderate-to-very severe COPD (50.7\% male; mean [standard deviation (SD)] age 62.1 [8.3] years) were enrolled and treated. Subject-reported actuation count and dose indicator-based actuation counts were consistent for $96.4 \%(132 / 137)$ of devices at the end of the treatment period (4 weeks) in the intent-to-treat (ITT) population and for all devices in the per-protocol (PP) population. The mean (SD) dose indicator-based actuation and subject-reported actuation counts in the ITT population $(n=137)$ were 113.4 (18.9) and 117.0 (19.0), respectively, with a mean (SD) difference of 3.6 (7.9). The mean (SD) dose indicatorbased actuation and subject-reported actuation counts in the PP population $(n=112)$ were $116.8(8.7)$ and 119.7 (8.1), respectively. There were no unexpected safety findings.

Conclusions: This study supported the accuracy, reliability, and utility of the dose indicator integrated into the GFF MDI device when used by patients with COPD.
\end{abstract}

Keywords: chronic obstructive pulmonary disease, co-suspension delivery technology, dose indicator, GFF MDI

\footnotetext{
${ }^{1}$ Upstate Pharmaceutical Research, Greenville, South Carolina.

${ }^{2}$ South Carolina Pharmaceutical Research, Spartanburg, South Carolina.

${ }^{3}$ Florida Premier Research Institute, LLC, Winter Park, Florida.

${ }^{4}$ Pearl - a member of the AstraZeneca Group, Durham, North Carolina.

${ }^{5}$ Pearl-a member of the AstraZeneca Group, Morristown, New Jersey.

${ }^{6}$ AstraZeneca, Gaithersburg, Maryland.
}

(c) Krishna Pudi, et al., 2018. Published by Mary Ann Liebert, Inc. This Open Access article is distributed under the terms of the Creative Commons Attribution Noncommercial License (http://creativecommons.org/licenses/by-nc/4.0/) which permits any noncommercial use, distribution, and reproduction in any medium, provided the original author(s) and the source are credited. 


\section{Introduction}

C HRONIC OBSTRUCTIVE PULMONARY DISEASE (COPD) was estimated to affect $\sim 329$ million people globally in 2010 . $^{(1)}$ COPD is associated with significant morbidity and mortality and has been predicted to become the fourth leading cause of death worldwide by $2030 .^{(2)}$

Inhaled bronchodilators are the principal treatment option for maintenance therapy in patients with COPD, including long-acting muscarinic antagonists (LAMAs) and long-acting $\beta_{2}$-agonists (LABAs). ${ }^{(3)}$ GFF MDI (Bevespi Aerosphere $\left.{ }^{(}\right)$, a LAMA/LABA fixed-dose combination of glycopyrrolate/ formoterol fumarate $18 / 9.6 \mu \mathrm{g}$ (equivalent to glycopyrronium/formoterol fumarate dihydrate $14.4 / 10 \mu \mathrm{g}$ ) delivered by metered dose inhaler using innovative co-suspension delivery technology, is approved in the United States for the long-term maintenance treatment of airflow obstruction in patients with COPD. ${ }^{(4)}$

Dose indicators in inhaler devices are intended to reduce patient error by allowing patients to track the number of actuations they have used. ${ }^{(5)}$ In line with U.S. Food and Drug Administration (FDA) guidance, dose indicators should be designed to be as close to $100 \%$ reliable as possible and should specifically avoid undercounting. The FDA further recommends that the functionality, reliability, and accuracy of dose indicators should be evaluated in clinical trials within the target population. ${ }^{(5)}$

The GFF MDI device incorporates the second generation TMAI-200 series dose indicator (Trudell Medical International AeroCount ${ }^{\circledR}$ top mounted actuation indicator), a commercially available dose indicator that has been integrated into the GFF MDI container closure system without device modification, except for attaching the dose indicator on the base of the GFF MDI canister with a canister label. The indicator uses a force mechanism to count down the remaining actuations. The count display is advanced after every 10 actuations, and numbers are displayed in increments of 20.

For GFF MDI, the starting dose indicator position is set to 130 , which accounts for 120 inhalations, 4 initial priming actuations, and 6 re-priming actuations. When the number of actuations remaining in the canister reaches 20 , the indicator displays the number 20 with red backing to indicate to the patient that it is time to refill their prescription.

The aim of the present study was to evaluate the performance of the dose indicator of GFF MDI when used by subjects with COPD.

\section{Patients and Methods}

\section{Study design}

This was an open-label, single-arm multicenter study (NCT02268396) conducted at 10 sites in the United States, with a duration of $\sim 6$ weeks per subject (a 1-2-week screening period, followed by a 4 -week treatment period) (Fig. 1). This study was conducted in accordance with Good Clinical Practice, including International Conference on Harmonisation Guidelines, the Declaration of Helsinki, and the United States Code of Federal Regulations. An Institutional Review Board approved the study protocol and consent forms, and written informed consent was obtained from all subjects before screening and study entry.

\section{Subject population}

Eligible subjects were $40-80$ years of age with COPD and current or former smokers with a smoking history of $\geq 10$ packyears and a minimum of 6 months' established clinical history of COPD (as defined by American Thoracic Society/European Respiratory Society guidelines). ${ }^{(6)}$ Subjects were required to have a forced expiratory volume in 1 second $\left(\mathrm{FEV}_{1}\right) /$ forced vital capacity ratio of $<0.70$, and a post-bronchodilator $\mathrm{FEV}_{1}$ value $\geq 30 \%$ and $<80 \%$ of predicted normal (calculated using the Third National Health and Nutrition Examination Survey reference equations ${ }^{(7,8)}$ ) that was also $\geq 750 \mathrm{~mL}$. Exclusion criteria included a clinically abnormal chest X-ray or computed tomography scan (if abnormalities were not due to COPD) and significant diseases other than COPD.

Subjects unable to comply with study procedures, including noncompliance with electronic diary (eDiary) completion, and those who required the use of a spacer device to compensate for poor hand-to-breath MDI coordination were also excluded.

Any eligible subjects who were using prohibited COPD medications (such as oral $\beta_{2}$-agonists and LABAs),

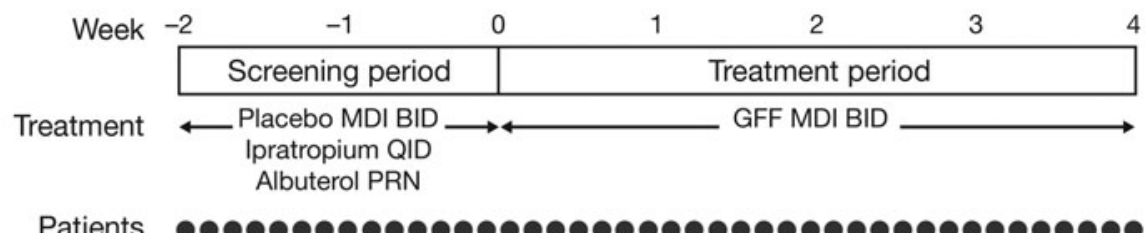

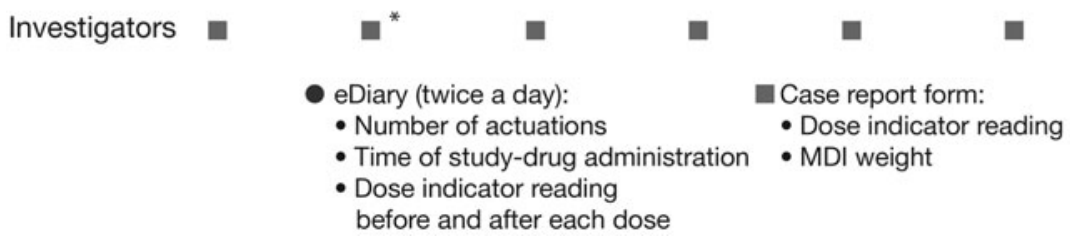

FIG. 1. Study design. BID, twice daily; GFF, glycopyrrolate/formoterol fumarate; MDI, metered dose inhaler; PRN, as required; QID, four times daily. *Compliance reassessment visit. 
cromoglycate or nedocromil inhalers, aclidinium, tiotropium, or fixed-dose combination treatment with an inhaled corticosteroid discontinued these medications for the duration of the trial and were switched to ipratropium bromide MDI four times daily and albuterol sulfate MDI as needed.

\section{Endpoints and assessments}

The primary endpoint was the percentage of devices that showed consistency between the subject-reported actuation count and the dose indicator-based actuation count at Week 4 (end of study). Owing to the dose indicator only advancing in increments of 10 actuations and displaying numbers in increments of 20 actuations, ${ }^{(4)}$ consistency was met when recorded within \pm 20 actuations. The subject-reported actuation count was the total number of actuations recorded by the subject in an eDiary, including priming shots before initial use and after cleaning. The dose indicator-based actuation count was defined as the total number of actuations of the MDI obtained by subtracting the dose indicator reading (recorded by the investigator) from 130 .

Safety assessments included physical examinations, electrocardiograms, vital sign measurements, clinical laboratory tests, and monitoring of adverse events (AEs). AEs that occurred on or after the date of the first dose of GFF MDI were considered treatment emergent. AEs that occurred between the time of signing the informed consent form and receiving the first dose of GFF MDI were recorded as medical history, unless they were serious treatmentemergent AEs (TEAEs).

\section{Screening period}

Subject compliance to treatment and eDiary use was assessed in the screening period through use of a placebo MDI. At the start of the screening period, subjects were issued with a handheld eDiary device (PROLogic nSpire Health) and placebo MDI, trained on their use, and instructed how to read and record information from the dose indicator. The information that subjects entered in the eDiary included information relating to dosing, i.e., the time of study-drug administration; the number of actuations used; and both pre-and post-dose dose indicator readings. Subjects used their MDI twice daily and entered information into the eDiary after each use. In addition, the eDiary also provided a weekly reminder to wash the actuator, which was confirmed by the subject.

MDI weight and dose indicator readings were recorded weekly at each study visit by the site staff. Figure 2 shows the position of the dose indicator in GFF MDI and the display window showing the number of actuations left in the device. MDI weight and dose indicator readings were recorded weekly at each study visit by the site staff. Study medication compliance (time of dosing) was checked at all study visits.

Subjects were reassessed for continued eligibility after 1-2 weeks. Subjects whose reported actuation count differed by $>6$ versus the weight-based actuation count during screening were issued a new placebo MDI and required to return to the clinic in 1 week for reassessment. Subjects who failed to complete $>80 \%$ of eDiary assessments, or whose subjectreported actuation count differed by $>6$ versus the weightbased actuation count after the second attempt, were considered screening failures.
SIDE VIEW

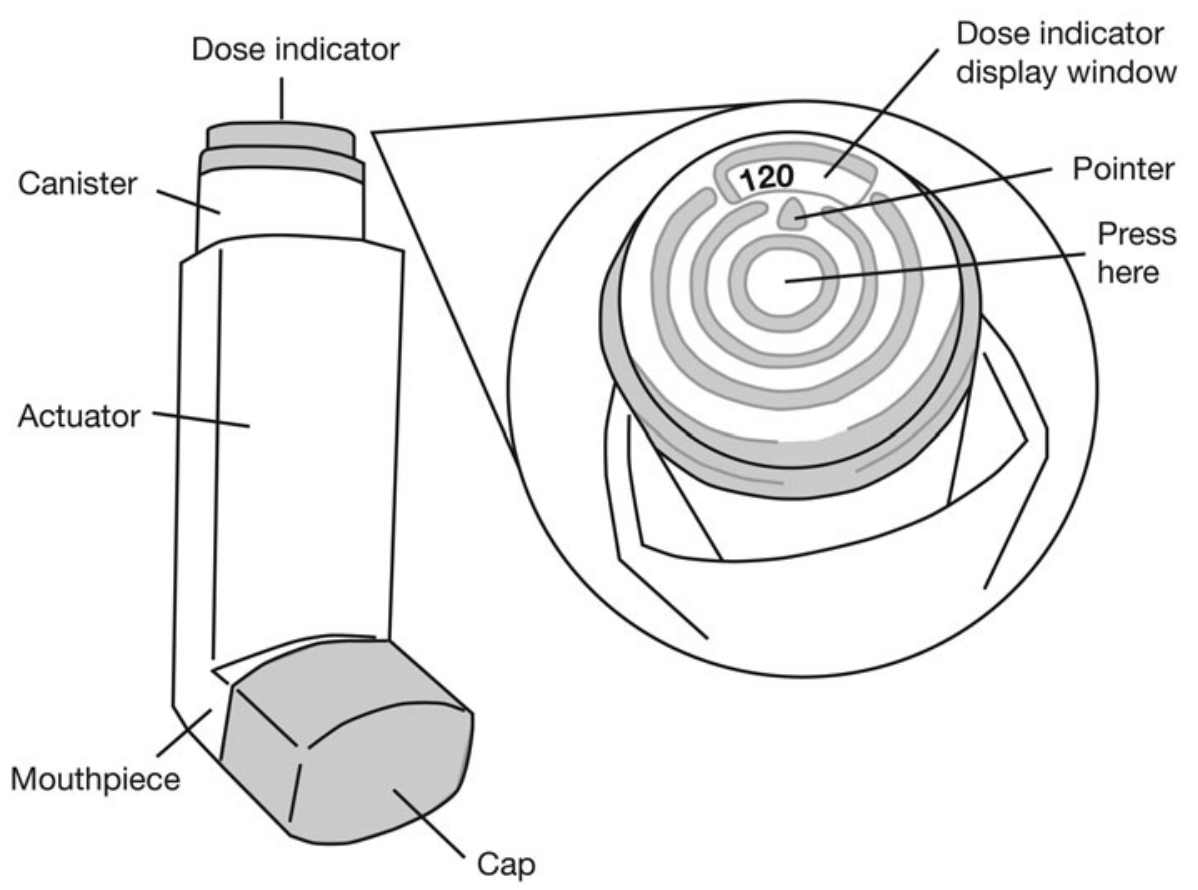

FIG. 2. Schematic of a GFF MDI device with the AeroCount ${ }^{\circledR}$ dose indicator. Reprinted by permission from AstraZeneca Pharmaceuticals LP. ${ }^{(4)}$ 

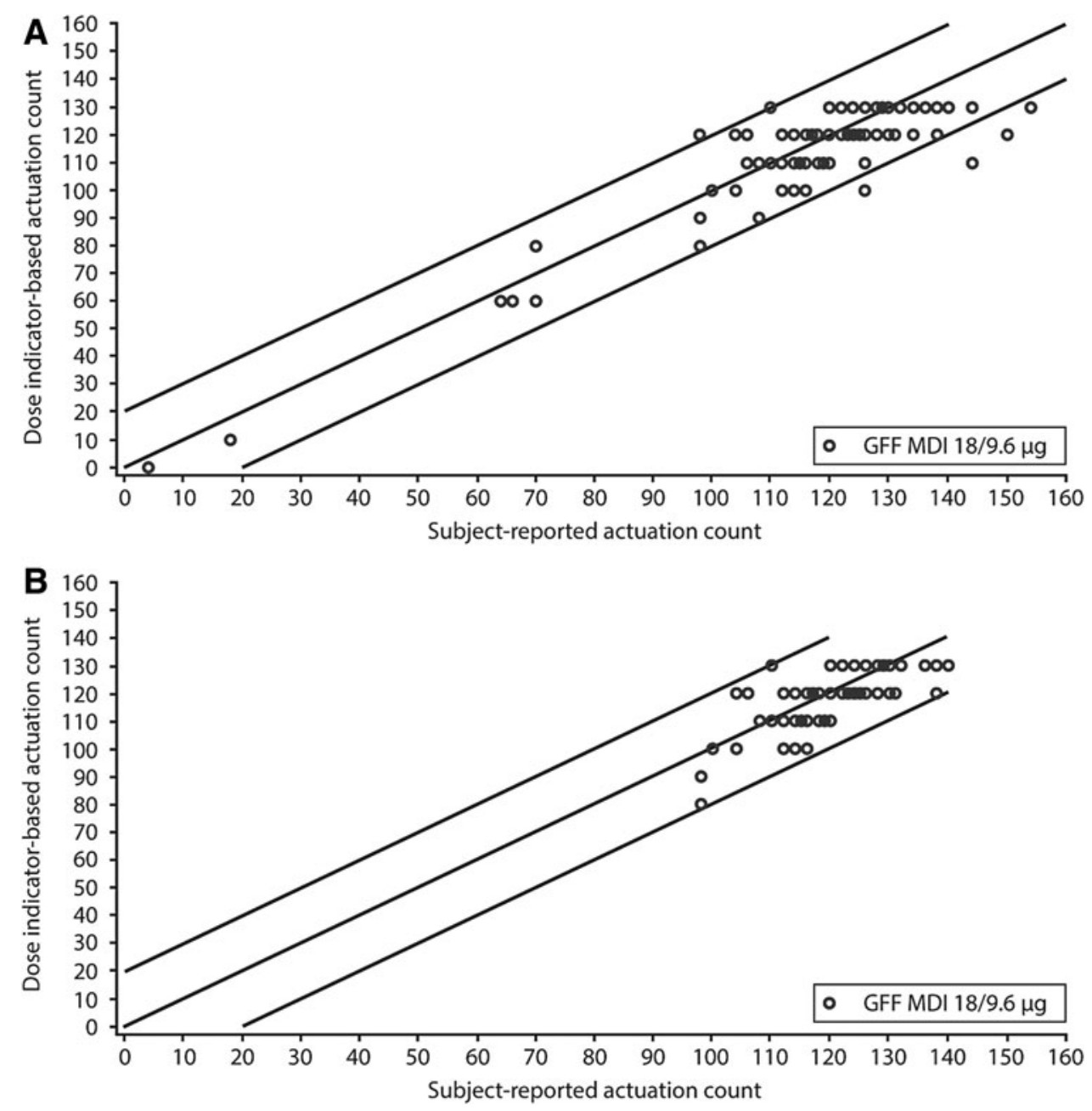

FIG. 3. Subject-recorded actuation count versus dose indicator-based actuation count at the last available visit for (A) ITT population $(n=137)$ and (B) PP population $(n=112)$. GFF, glycopyrrolate/formoterol fumarate; ITT, intent-to-treat; MDI, metered dose inhaler; PP, per-protocol.

\section{Treatment period}

Subjects compliant in the screening period continued into the treatment period and received GFF MDI, two inhalations twice daily, over a 4-week period, and recorded use in the eDiary as during the screening period.

\section{Statistical analyses}

The primary endpoint was analyzed in the intent-totreat (ITT) population (defined as all subjects enrolled into the treatment period and who used $\geq 10$ actuations of GFF MDI, as recorded in the eDiary) and in the perprotocol (PP) population (subjects who completed all visits with $\geq 80 \%$ eDiary compliance and who had no major protocol deviations that could affect dose indicator assessment).

Data for the primary endpoint were summarized descriptively and displayed using a scatter plot. AE data were summarized descriptively in the safety population, defined as all subjects who were enrolled into the treatment period and who received any amount of GFF MDI.

\section{Results}

In total, 138 subjects were enrolled and treated with GFF MDI, and $10(7.2 \%)$ withdrew before study completion due to: AEs $(n=3)$; administrative reasons $(n=2)$; withdrawal of consent $(n=1)$; loss to follow-up $(n=2)$; and discontinuation due to protocol-specific criteria $(n=2$; included lack of compliance with study visits $[n=1]$ and COPD exacerbation $[n=1])$. The ITT population was predominantly White $(94.9 \%)$ and around half $(50.7 \%)$ were male, with a mean (standard deviation [SD]) age of 62.1 (8.3) years. The mean (SD) disease duration of COPD was 7.7 (5.9) years. COPD severity in subjects was mostly moderate $(65.2 \%)$ or severe $(33.3 \%)$, and a small proportion of subjects had very severe COPD (1.4\%).

At the last available visit, dose indicator-based actuation count and subject-reported actuation count in the ITT population were consistent for $96.4 \%$ of devices (132 of 137 devices) (Fig. 3A). The mean (SD) dose indicatorbased actuation count $(n=137)$ was 113.4 (18.9), and mean (SD) subject-reported actuation count $(n=137)$ was $117.0(19.0)($ mean $[\mathrm{SD}]$ difference $=3.6$ [7.9]); note that 
Table 1. Overall Summary of Treatment-Emergent Adverse Events (Safety Population)

\begin{tabular}{lc}
\hline TEAEs & $\mathrm{n}=138$ \\
\hline$\geq 1$ TEAE & $38(27.5)$ \\
Treatment related & $6(4.3)$ \\
Leading to early discontinuation & $4(2.9)$ \\
Serious & $3(2.2)$ \\
Serious treatment related & 0 \\
Death during treatment period & 0 \\
or 14-day follow-up & \\
Most common ( 2 subjects) & \\
Worsening of COPD & $10(7.2)$ \\
Cough & $3(2.2)$ \\
Dyspnea & $2(1.4)$ \\
Nasopharyngitis & $2(1.4)$ \\
Nausea & $2(1.4)$ \\
Pain & $2(1.4)$ \\
Peripheral edema & $2(1.4)$ \\
Upper respiratory tract infection & $5(3.6)$ \\
Urinary tract infection & $2(1.4)$ \\
\hline
\end{tabular}

Data shown are $n(\%)$.

COPD, chronic obstructive pulmonary disease; TEAE, treatmentemergent adverse event.

due to the design of the dose indicator, each individual dose indicator-based actuation count was a multiple of 10 , but the average of these individual counts did not have to be a multiple of 10 . The median value for both counts was 120.0 .

In the PP population $(n=112)$, dose indicator-based actuation count and subject-reported actuation count at the last available visit were consistent for $100 \%$ of devices (Fig. 3B). The mean (SD) dose indicator-based actuation count was 116.8 (8.7), and the mean (SD) subject-reported actuation count was 119.7 (8.1). The median value for both counts was 120.0 .

Thirty-eight subjects $(27.5 \%)$ reported a total of 70 TEAEs during the study, including six subjects $(4.3 \%)$ who experienced TEAEs that the investigator considered to be treatment related. Three subjects $(2.2 \%)$ experienced serious TEAEs (COPD exacerbation $[n=2]$; metastatic neoplasm and metastatic pain [both in the same subject; $n=1]$ ). Four subjects withdrew due to TEAEs (COPD exacerbation $[n=3]$; atrial fibrillation $[n=1]$ ) (Table 1). No important trends were observed in changes from baseline in clinical laboratory results, vital signs, and electrocardiograms.

\section{Discussion}

Subject-reported actuation count and dose indicator-based actuation counts were highly consistent in both the ITT population (96.4\%) and PP population (100\%), demonstrating accuracy, functionality, and reliability of the dose indicator over the lifetime of the inhaler. There was very little undercounting in the ITT population, and no undercounting was observed in the PP population. Avoiding undercounting is important ${ }^{(5)}$ as it prevents patients from mistakenly assuming that they have medication left in their MDI when they do not.
Our study shows that the high reliability of this series of AeroCount dose indicators that was previously demonstrated in a simulated-use study ${ }^{(9)}$ is also achieved with GFF MDI in clinical trials in the intended target population of patients with COPD. The study duration was consistent with the anticipated lifetime of GFF MDI (i.e., 130 actuations to last 4 weeks of treatment, including priming actuations).

The safety and tolerability profile of GFF MDI in patients with COPD has previously been investigated in large, long-term, ${ }^{(10,11)}$ and short-term ${ }^{(12)}$ Phase III studies with a duration of up to 52 weeks. Consistent with these studies, no unexpected safety findings were identified in the present study.

In conclusion, this study supports the accuracy, reliability, and functionality of the dose indicator integrated into the GFF MDI device when used by patients with COPD.

\section{Acknowledgments}

This study was supported by Pearl-a member of the AstraZeneca Group. The authors thank all the subjects and their families, and the team of investigators, research nurses, and operations staff, involved in these studies. The authors thank Amber Doty for her support with the site training and coordination of the laboratory-based testing and Mervin Taylor for his technical insight into the dose indicator function. Medical writing support, under the direction of the authors, was provided by Joanna Wilson, PhD, of CMC CONNECT, a division of Complete Medical Communications Ltd., Glasgow, United Kingdom, which was funded by AstraZeneca, Cambridge, UK in accordance with Good Publication Practice (GPP3) guidelines. ${ }^{(13)}$

\section{Authors' Contributions}

A.M., C.R., E.S.R., P.M., and S.S. contributed to the conception or design of the study. K.P., F.F., and G.F. participated in the acquisition of the data. A.M., C.R., E.S.R., P.M., and S.S. participated in the analysis of the data. All authors contributed to the interpretation of the data, critically reviewed the article, and approved the final version for submission.

\section{Authors' Disclosure Statement}

K.P. and G.F. have no potential conflicts of interest to disclose. F.F. is an employee of Florida Premier Research Institute, LLC, and has performed clinical trials for AstraZeneca and Pearl-a member of the AstraZeneca Group. E.S.R., P.M., and A.M. are employees of Pearl-a member of the AstraZeneca Group. C.R. is an employee of Pearl-a member of the AstraZeneca Group and an employee of AstraZeneca. S.S. is an employee of AstraZeneca and former employee of Pearl-a member of the AstraZeneca Group.

\section{References}

1. Vos T, Flaxman AD, Naghavi M, Lozano R, Michaud C, Ezzati M, Shibuya K, Salomon JA, Abdalla S, Aboyans V, Abraham J, Ackerman I, Aggarwal R, Ahn SY, Ali 
MK, Al Mazroa MA, Alvarado M, Anderson HR, Anderson LM, Andrews KG, Atkinson C, Baddour LM, Bahalim AN, Barker-Collo S, Barrero LH, Bartels DH, Basañez MG, Baxter A, Bell ML, Benjamin EJ, Bennett D, Bernabé E, Bhalla K, Bhandari B, Bikbov B, Bin Abdulhak A, Birbeck G, Black JA, Blencowe H, Blore JD, Blyth F, Bolliger I, Bonaventure A, Boufous S, Bourne $\mathrm{R}$, Boussinesq $\mathrm{M}$, Braithwaite $\mathrm{T}$, Brayne $\mathrm{C}$, Bridgett L, Brooker S, Brooks P, Brugha TS, BryanHancock C, Bucello C, Buchbinder R, Buckle G, Budke $\mathrm{CM}$, Burch M, Burney $\mathrm{P}$, Burstein R, Calabria B, Campbell B, Canter CE, Carabin H, Carapetis J, Carmona L, Cella C, Charlson F, Chen H, Cheng ATA, Chou D, Chugh SS, Coffeng LE, Colan SD, Colquhoun S, Colson KE, Condon J, Connor MD, Cooper LT, Corriere M, Cortinovis M, de Vaccaro KC, Couser W, Cowie BC, Criqui MH, Cross M, Dabhadkar KC, Dahiya M, Dahodwala N, Damsere-Derry J, Danaei G, Davis A, De Leo D, Degenhardt L, Dellavalle R, Delossantos A, Denenberg J, Derrett S, Des Jarlais DC, Dharmaratne SD, Dherani M, Diaz-Torne C, Dolk H, Dorsey ER, Driscoll T, Duber H, Ebel B, Edmond K, Elbaz A, Ali SE, Erskine H, Erwin PJ, Espindola P, Ewoigbokhan SE, Farzadfar F, Feigin V, Felson DT, Ferrari A, Ferri CP, Fèvre EM, Finucane MM, Flaxman S, Flood L, Foreman K, Forouzanfar MH, Fowkes FGR, Franklin R, Fransen M, Freeman MK, Gabbe BJ, Gabriel SE, Gakidou E, Ganatra HA, Garcia B, Gaspari F, Gillum RF, Gmel G, Gosselin R, Grainger R, Groeger J, Guillemin F, Gunnell D, Gupta R, Haagsma J, Hagan H, Halasa YA, Hall W, Haring D, Haro JM, Harrison JE, Havmoeller R, Hay RJ, Higashi H, Hill C, Hoen B, Hoffman H, Hotez PJ, Hoy D, Huang JJ, Ibeanusi SE, Jacobsen KH, James SL, Jarvis D, Jasrasaria R, Jayaraman S, Johns N, Jonas JB, Karthikeyan G, Kassebaum N, Kawakami N, Keren A, Khoo JP, King $\mathrm{CH}$, Knowlton LM, Kobusingye O, Koranteng A, Krishnamurthi R, Lalloo R, Laslett LL, Lathlean T, Leasher JL, Lee YY, Leigh J, Lim SS, Limb E, Lin JK, Lipnick M, Lipshultz SE, Liu W, Loane M, Ohno SL, Lyons R, Ma J, Mabweijano J, MacIntyre MF, Malekzadeh R, Mallinger L, Manivannan S, Marcenes W, March L, Margolis DJ, Marks GB, Marks R, Matsumori A, Matzopoulos R, Mayosi BM, McAnulty JH, McDermott MM, McGill N, McGrath J, Medina-Mora ME, Meltzer M, Memish ZA, Mensah GA, Merriman TR, Meyer AC, Miglioli V, Miller M, Miller TR, Mitchell PB, Mocumbi AO, Moffitt TE, Mokdad AA, Monasta L, Montico M, Moradi-Lakeh M, Moran A, Morawska L, Mori R, Murdoch ME, Mwaniki MK, Naidoo K, Nair MN, Naldi L, Narayan KMV, Nelson PK, Nelson RG, Nevitt MC, Newton CR, Nolte S, Norman P, Norman R, O'Donnell M, O'Hanlon S, Olives C, Omer SB, Ortblad K, Osborne R, Ozgediz D, Page A, Pahari B, Pandian JD, Rivero AP, Patten SB, Pearce N, Padilla RP, Perez-Ruiz F, Perico N, Pesudovs K, Phillips D, Phillips MR, Pierce K, Pion S, Polanczyk GV, Polinder S, Pope CA, 3rd, Popova S, Porrini E, Pourmalek F, Prince M, Pullan RL, Ramaiah KD, Ranganathan D, Razavi H, Regan M, Rehm JT, Rein DB, Remuzzi G, Richardson K, Rivara FP, Roberts T, Robinson C, De Leon FR, Ronfani L, Room R, Rosenfeld LC, Rushton L, Sacco RL, Saha S, Sampson U, Sanchez-Riera L, Sanman E, Schwebel DC, Scott JG, Segui-Gomez M, Shahraz S, Shepard DS, Shin H, Shivakoti R, Singh D, Singh GM, Singh JA, Singleton
J, Sleet DA, Sliwa K, Smith E, Smith JL, Stapelberg NJ, Steer A, Steiner T, Stolk WA, Stovner LJ, Sudfeld C, Syed S, Tamburlini G, Tavakkoli M, Taylor HR, Taylor JA, Taylor WJ, Thomas B, Thomson WM, Thurston GD, Tleyjeh IM, Tonelli M, Towbin JA, Truelsen T, Tsilimbaris MK, Ubeda C, Undurraga EA, van der Werf MJ, van Os J, Vavilala MS, Venketasubramanian N, Wang M, Wang W, Watt K, Weatherall DJ, Weinstock MA, Weintraub R, Weisskopf MG, Weissman MM, White RA, Whiteford H, Wiersma ST, Wilkinson JD, Williams HC, Williams SR, Witt E, Wolfe F, Woolf AD, Wulf S, Yeh PH, Zaidi AK, Zheng ZJ, Zonies D, Lopez AD, Murray CJ, AlMazroa MA, and Memish ZA: Years lived with disability (YLDs) for 1160 sequelae of 289 diseases and injuries 1990-2010: A systematic analysis for the Global Burden of Disease Study 2010. Lancet. 2012;380: 2163-2196.

2. Mathers CD, and Loncar D: Projections of global mortality and burden of disease from 2002 to 2030. PLoS Med. 2006; 3:e442.

3. Global Initiative for Chronic Obstructive Lung Disease: Global Strategy for the Diagnosis, Management and Prevention of COPD. 2018. Available at http://goldcopd.org Accessed February 5, 2018.

4. AstraZeneca Pharmaceuticals LP: Bevespi Aerosphere ${ }^{\mathrm{TM}}$ Prescribing Information. 2017. Available at http:// azpicentral.com/bevespi/bevespi_pi.pdf Accessed February $5,2018$.

5. U.S. Department of Health and Human Services Food and Drug Administration and Center for Drug Evaluation and Research (CDER): Guidance for Industry: Integration of Dose-Counting Mechanisms into MDI Drug Products. 2003. Available at https://fda.gov/downloads/Drugs/Guidance ComplianceRegulatoryInformation/Guidances/UCM071731 .pdf Accessed February 8, 2018.

6. Celli BR, MacNee W, and ATS/ERS Task Force: Standards for the diagnosis and treatment of patients with COPD: A summary of the ATS/ERS position paper. Eur Respir J. 2004;23:932-946.

7. Hankinson JL, Odencrantz JR, and Fedan KB. Spirometric reference values from a sample of the general U.S. population. Am J Respir Crit Care Med. 1999;159: 179-187.

8. CDC National Center for Health Statistics. Third National Health and Nutrition Examination Survey III Spirometry Procedure Manual. 1988. https://wwwn.cdc.gov/nchs/ nhanes/nhanes3/manualsandreports.aspx Accessed June 21, 2018.

9. Scarrott P, Suggett J, Sieffert M, Armstrong K, and Mitchell J: Evaluation of count accuracy of a topmounted dose indicator for a pressurized metered-dose inhaler (pMDI): A study involving adult participants naïve to the product. J Aerosol Med Pulm Drug Deliv. 2015;28:A-7.

10. Hanania NA, Tashkin DP, Kerwin EM, Donohue JF, Denenberg M, O'Donnell DE, Quinn D, Siddiqui S, Orevillo C, Maes A, and Reisner C: Long-term safety and efficacy of glycopyrrolate/formoterol metered dose inhaler using novel Co-Suspension ${ }^{\mathrm{TM}}$ Delivery Technology in patients with chronic obstructive pulmonary disease. Respir Med. 2017;126:105-115.

11. Martinez FJ, Rabe KF, Ferguson GT, Fabbri LM, Rennard S, Feldman GJ, Sethi S, Spangenthal S, Gottschlich GM, Rodriguez-Roisin R, Arora S, Siler TM, 
Siddiqui S, Darken P, Fischer T, Maes A, Golden M, Orevillo C, and Reisner C: Efficacy and safety of glycopyrrolate/formoterol metered dose inhaler formulated using co-suspension delivery technology in patients with COPD. Chest. 2017;151:340-357.

12. Reisner C, Gottschlich G, Fakih F, Koser A, Krainson J, Delacruz L, Arora S, Feldman G, Pudi K, Siddiqui S, Orevillo C, Maes A, St. Rose E, and Martin U: 24-H bronchodilation and inspiratory capacity improvements with glycopyrrolate/formoterol fumarate via co-suspension delivery technology in COPD. Respir Res. 2017;18:157.

13. Battisti WP, Wager E, Baltzer L, Bridges D, Cairns A, Carswell CI, Citrome L, Gurr JA, Mooney LA, Moore BJ, Peña T, Sanes-Miller CH, Veitch K, Woolley KL, and Yarker YE: Good publication practice for communicating company-sponsored medical research: GPP3. Ann Intern Med. 2015;163:461-464.
Received on March 26, 2018

in final form, August 3, 2018

Reviewed by: Gur Jai Pal Singh

Kurt Nikander

Address correspondence to:

Krishna Pudi, MD

Upstate Pharmaceutical Research

30 Pointe Circle

Greenville, SC 29615

E-mail:kbpudi@gmail.com 